\title{
An Empirical Study of Host Social Media on the Intercultural Adaptation of Preparatory International Students in China: A Case Study of Shandong University
}

\begin{abstract}
XIE Na
Shandong University, Shandong, China

This thesis probes into the current situation of host social media usage and intercultural adaptation of preparatory international students in China. Study covered 208 preparatory international students in total was conducted, with subject observation, structured interview, and questionnaire, in Shandong University, which is considered as one of the most representative institutions providing high-level preparatory education for international students in China. Field data collected were analyzed descriptively in the form of frequencies, tables, and percentages. Taken all that have been analyzed in this thesis, findings strongly suggest that the main factors influencing international students' intercultural adaptability include host social media usage, intercultural experience, mandarin level, and cultural distance. Results also indicate significant correlation between host social media usage and intercultural adaptation: students who frequently use host social media to chat with Chinese perform better at intercultural adaptation; those who are more dependent and satisfied with host social media are more adaptive as well, the same goes to students who use host social media more frequently to get information or socialize. Consequently, this study suggests necessary promotion of host social media for international students in China.
\end{abstract}

Keywords: preparatory international students, host social media, intercultural adaptation, empirical study

\section{Introduction}

This study explores the impact of host social media on intercultural adaptation of international students in China, taking students in Shandong University preparatory foreign student teaching department as case study. It is premised on the assumption that in the contemporary world, people often change with the environment where social media exerts great influence. With the rapid development of mobile internet technology and the wide-spread use of large-screen smart phones, online social media have become the main tools for daily communication in China, among them there are Microblog, WeChat, and QQ. Tencent's 2018 Quarterly Report showed that WeChat's monthly active users have reached 1.04 billion already, and it is still gaining in popularity. Therefore, it is safe to say that social media have profoundly changed people's life, including those international students in China.

Since 2000, the situation of international students' intercultural adaptation in China had been widely studying. However, theoretical and empirical studies were originated from the West, which focused mostly on macro-policy and normative research, while few people pay attention to the status quo of host social media

XIE Na, Reading Doctoral Student, College of International Education, Shandong University, Shandong, China. 
usage of international students in China, and its influence on intercultural adaptation. As such, this study is going to explore how host social media influences foreign students' intercultural adaptability. With findings from the practical field of ethnography and replicable scientific generalization, this thesis expects to provoke more relevant case studies to shape policies on international students in China.

\section{Study Background}

The education for international students is not only of great political significance and value, but also an important force for promoting economic growth and cultural exchanges. According to the latest statistics from the US authority National Association of Foreign Student Affairs (NAFSA), international students in the 2016-2017 academic year generated \$36.9 billion economic benefits and filled in more than 4.5 million job gaps. Also, the latest American Open Doors Report (2017) pointed out that international students have made outstanding contributions to American scientific research and educational development. In order to give full play to the educational function of international students and improve the education quality they receive, primary destination countries have established preparatory education. For instance, Australia has, in the form of regulations, promulgated the National Benchmark for preparatory courses to ensure that oversea students enjoy high-quality study and services. Today, an increasing number of traditional source countries of international students, such as Singapore, Malaysia, and mainland China, have joined the ranks of international education market competition, which has gradually led to the counter-cyclical phenomenon in the market.

Due to China's fast-growing economy and profound cultural heritage, the number of international students coming into China for further study is rapidly on the rise. According to statistics from the Ministry of Education of the People's Republic of China in 2017, there were a total of 0.49 million international students from 204 countries and regions studying in China, making China the most popular country for abroad study in Asia. Among them, Chinese government had provided scholarship for 58,600 students, accounting for $11.97 \%$ of the total. To effectively ensure the education quality of international students who are given scholarship by Chinese government and improve the utilization of scholarship, the Ministry of Education had stipulated in 2010 that those who are awarded scholarship must receive comprehensive preparatory education before starting professional learning. By far, China has set up preparatory departments in Shandong University and other universities to provide preparatory education for international students.

Intercultural adaptation is the primary problem faced by international students when entering different cultures. Not only does their adaptability influence individual development, but also the effectiveness of family and national investment, especially for those younger preparatory students. The majority of preparatory international students supported by Chinese government scholarship came from economically backward countries in Asia, Africa, or Latin America. They were young, with little social experience and poor learning ability, and in the meantime, lacked basic understanding of Chinese culture. Before coming to China, most of them had just received little basic education, which made it impossible for them to adapt to new environment in a short period. Therefore, the study of intercultural adaptation of pre-university international students in China is of practical significance.

In such an information age, the impact of media environment on personality-shaping cannot be ignored, especially when the environment changes. Different from previous research, this study is aiming at exploring international students' current situation of intercultural adaptability from the perspective of host social media usage, and searching for ways to help them overcome problems they are now facing. 


\section{Presentation of the Question}

The study of intercultural adaptation could be dated back to 1970s in the United States, and had been accumulating a wealth of research findings. Generally speaking, the research object covers two categories: long-term migrant refugees and short-term residents. For short-term residents, "intercultural adaptation" often means that individuals make conscious and inclined behavior choice based on self-cognition and emotional attachment to the two cultures. Study on short-term residents' intercultural adaptation has its advantages over that of long-term migrant refugees due to the convenience and concentration of sample collection. In China, with education level being constantly improved, the scale of international students by now has been rapidly expanded, but the current situation of their intercultural adaptation is overwhelmingly negative. Just because of this, academic research on this subject has received greater attention in recent years, aiming to excavate the influencing factors and provide specific measures to help international students.

According to bibliographic search, there exist different opinions on the influencing factors of intercultural adaptation, among them cultural distance and existing intercultural experience are widely studied. As for the characteristics of oversea pre-university students in China, there are no significant differences in education, age, professional status, and so on. Therefore, this study selects gender, cultural distance, intercultural experience, language proficiency, and host social media usage as the main influencing factors.

Cultural distance refers to the degree of cultural differentiation between the source country and the destination country, especially reflecting in values, norms, systems, religious beliefs, etc. In terms of the relation between cultural distance and cross-cultural adaptation, it is generally believed that the greater the cultural distance is, the more efforts need to be made to overcome differences, and the more difficult it is to adapt, the longer it will take. For example, Ward and Kennedy (1999) found that Malaysian students studying in Singapore experienced fewer cultural adaptation difficulties than those studying in New Zealand. According to the nationality of participants, this study divides the origin countries into two categories: Asian country and non-Asian country.

Intercultural experience includes both foreign life experiences and social interactions with local people. It is generally believed that the richer the intercultural experience one has gained, especially through frequent interaction with local people, the faster he/she can adapt to a foreign environment.

Language proficiency refers to preparatory students' mandarin level, which are divided into two categories: HSK $^{1} 4$ or above and below.

Intercultural adaptation is also related to host social media usage. With the continuous innovation of information technology, this kind of influence is gradually maximized. Some scholars have pointed out that the involvement of mass media promotes the process of adaptation to some extent. The study of intercultural adaptation from the perspective of communication began in the 1920s. Scholar Parker (1922) examined the socialized influence of immigrant newspapers on European immigrant groups in the United States, and proposed that immigrant newspapers were a double-edged sword. Kim YoungYun (1987), a Korean scholar, put forward the concepts of "ethnic media" and "host media" in 1990s, among them the latter refers to local media of the host country and whose use can accelerate intercultural adaptation. As what scholars have

\footnotetext{
1 The Chinese Proficiency Test (HSK) is an international Chinese proficiency test for students who test the Chinese proficiency of non-native Chinese speakers (including foreigners, overseas Chinese and Chinese minority candidates), including HSK1-6 and HSK4 is the basic language requirement for entering university in China.
} 
discussed, social media is an important part of host media. In China, host social media refers to the media widely used in mainland China, one of the well-known representatives goes to WeChat. In recent years, more and more international students have joined the WeChat Group and become active users, which do exert profound impacts on their lives. Based on this, a survey was conducted to check out the influence of host social media on students' intercultural adaptation.

\section{Study Methodology}

On the theoretical framework that media's influences on human life are getting increasingly significant, research of this thesis was carried out by using social media to acquire the interconnection between media and education, which to some extent, could be helpful for promoting the development of international students' education and the understanding of multiculturalism. Furthermore, study also worked on the postulate that after entering China, international students would like to know more about China's economic and social conditions, and seek social and emotional support through using host social media.

To operationalize this theoretical framework, study applied relevant social science data-gathering techniques, including extensive interviews, questionnaires, and participants observation. After that, descriptive statistics including frequencies, tables, and percentages are employed in data analysis. There were three questions guiding the study: What is the current status of host social media use for international students in China? What is the relation between host social media usage and intercultural adaptation? What are the other factors that influence intercultural adaptation?

Shandong University was selected as case study because it typifies what is common among many Chinese government scholarship education bases for pre-university international students. Since 2005, Shandong University had been designated by the China Scholarship Council as a pilot institution with government scholarships given to students coming to China for preparatory education. At present, Shandong University has successfully accepted and trained 13 prep-university international students, which could be enlightening to this thesis.

Two hundred and eight valid questionnaires were collected, and the effective recovery rate was $87.4 \%$. Among those effective questionnaires, some were distributed to students through WeChat Group in the form of online electronic questionnaire, others were in printed paper. Besides, study was supplemented with participant interviews at the same time. The questionnaire covers three parts. First part is the control variable, which mainly includes gender, nationality, intercultural experience, and mandarin level. Second part is the independent variable, which is host social media usage, including the average daily use time and host social media usage evaluation scale. The average daily use time is divided into two categories: average daily use time and average daily interaction time with Chinese. Host social media usage evaluation scale is a self-made scale with a total of 21 descriptive items so as to do factor analysis, as shown in Tables 1 and 2. The result shows that the Kaiser-Meyer-Olkin (KMO) Test value is 0.850 , more than 0.70 , indicating that the scale is suitable for factor analysis. The Bartlett Sphericity Test's approximate chi-square value is 1766.149 , and the significant probability is $0.000(p<0.01)$. That is to say, the zero hypothesis of Bartlett Sphericity Test is rejected and the validity structure of the scale is considered suitable for factor analysis. In the process of factor analysis, four factors are extracted by principal component analysis and rotated by the maximum variance method. As shown in Table 1, the total variance interpretation rate of four factors is 72.258 , greater than 60 , which shows that the scale has good validity. These four factors are named as media satisfaction, media dependence, media access to 
information, and media social interaction. Specific structure and reliability of the scale are shown in Table 2. The third part is dependent variable, the intercultural adaptation. This paper adopts Wilson's (2013) intercultural adaptation scale, which has 21 options and is divided into five dimensions: interpersonal communication, academic/work performance, personal interests \& community involvement, ecological adaptation, and language proficiency; the structure and reliability of the scale are as shown in Table 3. And these two scales in the questionnaire are calculated with the mean value using the Richter Five-Metric scale (1 = "Strongly disagree", $5=$ "Strongly agree"). In addition to the variables involved in the scale, the other variables and their encoding are shown in Table 4.

Table1

Rotation After Host Social Media Usage Evaluation Scale' Factor Analysis

\begin{tabular}{|c|c|c|c|c|}
\hline \multirow[t]{2}{*}{ Rotational component matrix } & & & & \\
\hline & \multicolumn{4}{|c|}{ Composition } \\
\hline & Factor 1 & Factor 2 & Factor 3 & Factor 4 \\
\hline Using WeChat is entertaining. & & & & 0.696 \\
\hline I can meet new friends through WeChat. & & & & 0.613 \\
\hline I can keep in touch with my friends through WeChat. & & & & 0.746 \\
\hline WeChat has become part of my daily routine in China. & & & & 0.731 \\
\hline I am proud to tell people I am on WeChat. & & 0.858 & & \\
\hline I feel out of touch when I have not logged onto WeChat for a day. & & 0.843 & & \\
\hline I would be sorry if WeChat shut down. & & 0.740 & & \\
\hline $\begin{array}{l}\text { I always want to use WeChat and expect to receive new information } \\
\text { and friend updates. }\end{array}$ & & 0.777 & & \\
\hline $\begin{array}{l}\text { I can get information about China and learning Chinese through the } \\
\text { WeChat public account. }\end{array}$ & 0.890 & & & \\
\hline $\begin{array}{l}\text { I can get information about China and learning Chinese through the } \\
\text { WeChat circle of friends. }\end{array}$ & 0.925 & & & \\
\hline $\begin{array}{l}\text { I can get information about China and learning Chinese through the } \\
\text { WeChat Groups. }\end{array}$ & 0.879 & & & \\
\hline $\begin{array}{l}\text { I can get information about China and learning Chinese through } \\
\text { chatting with Chinese on WeChat. }\end{array}$ & 0.883 & & & \\
\hline $\begin{array}{l}\text { I will comment on and like other people's remarks in the WeChat } \\
\text { friends circle. }\end{array}$ & & & 0.779 & \\
\hline $\begin{array}{l}\text { I will post information on my study and life in China in the WeChat } \\
\text { circle of friends. }\end{array}$ & & & 0.864 & \\
\hline $\begin{array}{l}\text { The information I sent from the WeChat friends circle is generally } \\
\text { praised and commented by WeChat friends. }\end{array}$ & & & 0.865 & \\
\hline Explain the variance $(\%)$ & 23.24 & 18.98 & 15.10 & 14.94 \\
\hline
\end{tabular}

Table 2

Analysis of the Structure and Reliability of the Host Social Media Usage Evaluation Scale

\begin{tabular}{lll}
\hline Dimension & Items & Cronbachs alpha based on standardization terms \\
\hline Media satisfaction & $1 / 2 / 3 / 4$ & 0.724 \\
Media dependence & $5 / 6 / 7 / 8$ & 0.850 \\
Media access to information & $9 / 10 / 11 / 12$ & 0.947 \\
Media social interaction & $13 / 14 / 15$ & 0.838 \\
Overall HMTS-R & $1-15$ & 0.869 \\
\hline
\end{tabular}


Table 3

Structure and Reliability of Intercultural adaptation Scale

\begin{tabular}{lll}
\hline Dimension & Items & Cronbachs alpha based on standardization terms \\
\hline Interpersonal communication & $1 / 3 / 6 / 11 / 13 / 16 / 21$ & 0.805 \\
Academic/work Performance & $2 / 7 / 12 / 17$ & 0.755 \\
Personal interests \&community involvement & $4 / 8 / 14 / 18$ & 0.732 \\
Ecological adaptation & $5 / 9 / 15 / 19$ & 0.731 \\
Language proficiency & $10 / 20$ & 0.738 \\
Overall SCAS-R & $1-21$ & 0.929 \\
\hline
\end{tabular}

Table 4

Variable and Its Coding

\begin{tabular}{|c|c|c|c|c|}
\hline Variable & Dimension & Frequency & Frequency & Coding description \\
\hline \multirow{2}{*}{ Gender } & Female & 111 & 53.37 & \multirow{2}{*}{ Female $=1 ;$ male $=0$} \\
\hline & Male & 97 & 46.63 & \\
\hline \multirow{2}{*}{ Nationality area } & Asia & 79 & 37.98 & \multirow{2}{*}{ Asia $=1 ;$ non-Asian $=0$} \\
\hline & Non-Asian & 129 & 62.02 & \\
\hline \multirow{2}{*}{ Intercultural experience } & Have & 102 & 49.04 & \multirow{2}{*}{ Have $=1 ;$ no $=0$} \\
\hline & No & 106 & 50.96 & \\
\hline \multirow{2}{*}{ Mandarin level } & HSK 4 or above & 147 & 70.67 & \multirow{2}{*}{ HSK 4 or above $=1 ;$ HSK 4 below $=0$} \\
\hline & HSK4 below & 61 & 29.33 & \\
\hline \multirow{4}{*}{ Average daily use time } & Less than 1 hours & 33 & 15.87 & \multirow{4}{*}{$\begin{array}{l}\text { Less than one hour }=1 \text {; one to two } \\
\text { hours }=2 ; \text { two to three hours }=3 \text {; more } \\
\text { than three hours }=4\end{array}$} \\
\hline & One to two hours & 62 & 29.81 & \\
\hline & Two to three hours & 49 & 23.56 & \\
\hline & More than 3 hours & 64 & 30.77 & \\
\hline \multirow{4}{*}{$\begin{array}{l}\text { Average daily interaction } \\
\text { time with Chinese }\end{array}$} & Less than one hours & 150 & 72.12 & \multirow{4}{*}{$\begin{array}{l}\text { Less than one hours }=1 \text {; one to two } \\
\text { hours }=2 \text {; two to three hours }=3 \text {; more } \\
\text { than three hours }=4\end{array}$} \\
\hline & One to two hours & 42 & 20.19 & \\
\hline & Two to three hours & 9 & 4.33 & \\
\hline & More than three hours & 7 & 3.37 & \\
\hline
\end{tabular}

\section{Representation and Analyses of Field Data}

\section{The Host Social Media Usage Status}

As shown in Table 5, the average daily time spent on host social media is $2.69(>2)$, and the time spent chatting with Chinese is $1.39(<2)$, which means that most students spend more than two hours a day (on average) on host social media and less than an hour chatting with Chinese. According to further classification, male spends more time than female; students from non-Asian regions spend longer than those from Asia; students with intercultural experience spend much more time on host social media but less chatting with Chinese than those without; students with higher Chinese proficiency spend less time on host social media, but more on chatting with Chinese. The value of overall media satisfaction is $3.84(>3)$, indicating that most international students are satisfied with Chinese media. Specifically, male, students from non-Asian country, or those with little intercultural experience and lower Chinese proficiency, have higher satisfaction. From the aspect of media dependence, the overall dependence degree is $3.19(>3)$, which indicates abundantly that female, students with little intercultural experience and lower Chinese proficiency are more dependent on host social media. In terms of the use of media for information and social interaction, male, students from Asia, and those without intercultural experience or with lower Chinese proficiency are more active. 
Table 5

Status of Use of Host Social Media and Intercultural Adaptation (Mean)

\begin{tabular}{|c|c|c|c|c|c|c|c|c|c|c|c|c|c|}
\hline & & \multicolumn{6}{|c|}{ Status of use of host social media } & \multicolumn{6}{|c|}{ Intercultural adaptation } \\
\hline & & $\begin{array}{l}\text { Average } \\
\text { daily } \\
\text { use time }\end{array}$ & $\begin{array}{l}\text { Average } \\
\text { daily } \\
\text { interaction } \\
\text { time with } \\
\text { Chinese }\end{array}$ & $\begin{array}{l}\text { Media } \\
\text { satisfaction }\end{array}$ & $\begin{array}{l}\text { Media } \\
\text { dependence }\end{array}$ & $\begin{array}{l}\text { Media } \\
\text { access to } \\
\text { information }\end{array}$ & $\begin{array}{l}\text { Media } \\
\text { social } \\
\text { interaction }\end{array}$ & $\begin{array}{l}\text { Overall } \\
\text { situation }\end{array}$ & $\begin{array}{l}\text { Interpersonal } \\
\text { communication }\end{array}$ & $\begin{array}{l}\text { Academic } \\
\text { performan } \\
\text { ce }\end{array}$ & $\begin{array}{l}\text { Personal } \\
\text { interests \& } \\
\text { community } \\
\text { involvement }\end{array}$ & $\begin{array}{l}\text { Ecological } \\
\text { Adaptation }\end{array}$ & $\begin{array}{l}\text { Language } \\
\text { proficiency }\end{array}$ \\
\hline \multicolumn{2}{|l|}{ Overall mean } & 2.69 & 1.39 & 3.84 & 3.19 & 3.70 & 3.43 & 3.67 & 3.57 & 3.80 & 3.65 & 3.62 & 3.73 \\
\hline \multirow{2}{*}{ Gender } & Female & 2.72 & 1.43 & 3.93 & 3.17 & 3.76 & 3.43 & 3.69 & 3.62 & 3.82 & 3.70 & 3.65 & 3.69 \\
\hline & Male & 2.67 & 1.35 & 3.77 & 3.21 & 3.65 & 3.43 & 3.66 & 3.52 & 3.78 & 3.61 & 3.59 & 3.78 \\
\hline \multirow{2}{*}{$\begin{array}{l}\text { Nationality } \\
\text { area }\end{array}$} & Asia & 2.68 & 1.37 & 3.93 & 3.17 & 3.76 & 3.43 & 3.69 & 3.62 & 3.82 & 3.70 & 3.65 & 3.69 \\
\hline & $\begin{array}{l}\text { Non-Asi } \\
\text { an }\end{array}$ & 2.70 & 1.40 & 3.77 & 3.21 & 3.65 & 3.43 & 3.66 & 3.52 & 3.78 & 3.61 & 3.59 & 3.78 \\
\hline \multirow{2}{*}{$\begin{array}{l}\text { Intercultural } \\
\text { experience }\end{array}$} & Have & 2.77 & 1.32 & 3.87 & 3.14 & 3.66 & 3.40 & 3.73 & 3.67 & 3.85 & 3.73 & 3.70 & 3.72 \\
\hline & No & 2.61 & 1.45 & 3.82 & 3.24 & 3.74 & 3.47 & 3.62 & 3.47 & 3.75 & 3.58 & 3.54 & 3.76 \\
\hline \multirow{2}{*}{$\begin{array}{l}\text { Mandarin } \\
\text { level }\end{array}$} & $\begin{array}{l}\text { HSK4 } \\
\text { or above }\end{array}$ & 2.84 & 1.387 & 3.79 & 3.33 & 3.67 & 3.47 & 3.62 & 3.52 & 3.75 & 3.58 & 3.55 & 3.69 \\
\hline & Below & 2.32 & 1.393 & 3.98 & 2.85 & 3.79 & 3.34 & 3.81 & 3.69 & 3.92 & 3.82 & 3.78 & 3.85 \\
\hline
\end{tabular}




\section{Intercultural Adaptation}

In general, intercultural adaptation in the study shows good validity. Specifically, male, the Asian, students with intercultural experience or lower Chinese proficiency are a little bit better. From the division of each dimension, male, the Asian, students with intercultural experience are slightly better in interpersonal communication, academic performance, personal interests \& community involvement, and ecological adaptation. In the dimension of language proficiency, the opposite is true, and students with low language levels have better adaptability.

\section{Regression Analysis: Factors Affecting Intercultural Adaptation}

The multivariate linear regression method is used for data analysis, and the results are shown in Table 6. In the model, statistically five factors exert significant impact on the intercultural adaptation of international students: average daily use time, average daily interaction time with Chinese, media satisfaction, media dependency, and media access to information, whose $\beta$ index are $-0.0754^{*}, 0.107^{*}, 0.191^{* *}, 0.126^{* *}$, and $0.107^{*}$ respectively. Except for the variable "average daily use time", the remaining four have a positive effect. That is, the longer the daily use time, the lower the level of intercultural adaptation, while with the enhancement of media satisfaction and dependency, the more frequent the use of host social media to obtain information, the better the intercultural adaptation.

Model II to Model VI mainly analyze the influence of each variable on the intercultural adaptation to each dimension. In the Model II, the influence of intercultural experience, average daily interaction time with Chinese, media satisfaction, media dependence, and media social interaction on interpersonal communication adaptation is statistically significant, and their $\beta$ indexes are $0.211^{* *}, 0.143^{*}, 0.238^{* * *}, 0.124^{*}, 0.130^{*}$ respectively, indicating that students, with intercultural experience, more interaction with Chinese, higher media satisfaction or dependency, and more frequent media social interaction, perform better in interpersonal adaptation.

Model III shows that there exists statistical significance in media satisfaction and dependency on academic performance, and the beta indexes are $0.223^{* *}$ and $0.113^{*}$ respectively. It can be concluded that academic adaptability rises along with the improvement of media satisfaction and dependence.

In Model IV, the influences of intercultural experience, mandarin level, average daily interaction time with Chinese, media satisfaction, media dependence, and media access to information on personal interest/campus integration are statistically significant, and their $\beta$ indexes are $0.189^{*},-0.224^{*}, 0.149^{*}, 0.181^{*}, 0.143^{* *}, 0.147^{* *}$ respectively. International students with intercultural experience, lower mandarin level, interacting longer with the Chinese, higher media satisfaction or dependency, and more frequent media social interaction are better at maintaining their personal interests and integrating into campus life.

In Model V, the influences of intercultural experience, mandarin level, average daily interaction time with Chinese, media satisfaction, media dependence, and media access to information on the ecological adaptation are statistically significant, and their $\beta$ indexes are $0.193^{*},-0.216^{*}, 0.134^{*}, 0.171^{*}, 0.163^{* *}, 0.126^{*}$. Conclusion could be drawn out of this model that international students, with intercultural experience, lower mandarin level, higher media satisfaction or dependency, more frequent media access to information, and more time interacting with Chinese, can better adapt to China's ecological environment. However, in Model VI, each variable of language proficiency statistically shows no significant effect. 
Table 6

Regression Analysis of Influencing Factors of Intercultural Adaptation

\begin{tabular}{|c|c|c|c|c|c|c|}
\hline & $\begin{array}{l}\text { Dependent } \\
\text { variable: } \\
\text { Intercultural } \\
\text { Adaptation I } \\
\end{array}$ & $\begin{array}{l}\text { Dimension 1: } \\
\text { Interpersonal } \\
\text { Communication II }\end{array}$ & $\begin{array}{l}\text { Dimension 2: } \\
\text { Academic } \\
\text { Performance III }\end{array}$ & $\begin{array}{l}\text { Dimension 3: } \\
\text { Personal interest } \\
\text { \& Community } \\
\text { Involvement IV } \\
\end{array}$ & $\begin{array}{l}\text { Dimension 4: } \\
\text { Ecological } \\
\text { Adaptation V }\end{array}$ & $\begin{array}{l}\text { Dimension 5: } \\
\text { Language } \\
\text { Proficiency VI }\end{array}$ \\
\hline \multirow[t]{2}{*}{$\begin{array}{l}\text { Gender (female } \\
=1 \text { ) }\end{array}$} & -0.00308 & -0.0503 & -0.00787 & -0.0493 & -0.0195 & 0.112 \\
\hline & $(0.0756)$ & $(0.0782)$ & $(0.0857)$ & $(0.0845)$ & $(0.0876)$ & $(0.117)$ \\
\hline \multirow[t]{2}{*}{$\begin{array}{l}\text { Nationality (Asia } \\
\text { Country = 1) }\end{array}$} & -0.134 & -0.133 & -0.175 & -0.0856 & -0.102 & -0.175 \\
\hline & $(0.0782)$ & $(0.0809)$ & $(0.0886)$ & $(0.0874)$ & $(0.0905)$ & $(0.121)$ \\
\hline \multirow[t]{2}{*}{$\begin{array}{l}\text { Intercultural } \\
\text { experience }(\text { have }=1)\end{array}$} & 0.140 & $0.211^{* *}$ & 0.119 & $0.189^{*}$ & $0.193^{*}$ & -0.0109 \\
\hline & $(0.0756)$ & $(0.0782)$ & $(0.0856)$ & $(0.0844)$ & $(0.0875)$ & $(0.117)$ \\
\hline \multirow{2}{*}{$\begin{array}{l}\text { Mandarin proficiency } \\
(\text { Hsk4 or above }=1)\end{array}$} & -0.172 & -0.163 & -0.138 & $-0.224^{*}$ & $-0.216^{*}$ & -0.119 \\
\hline & $(0.0887)$ & $(0.0917)$ & $(0.101)$ & $(0.0991)$ & $(0.103)$ & $(0.137)$ \\
\hline \multirow{2}{*}{$\begin{array}{l}\text { Average daily use } \\
\text { time }\end{array}$} & $-0.0754^{*}$ & -0.0476 & -0.0720 & -0.0749 & -0.0848 & -0.0975 \\
\hline & $(0.0372)$ & $(0.0385)$ & $(0.0422)$ & $(0.0416)$ & $(0.0431)$ & $(0.0574)$ \\
\hline \multirow[t]{2}{*}{$\begin{array}{l}\text { Average daily } \\
\text { interaction time with } \\
\text { Chinese }\end{array}$} & $0.107^{*}$ & $0.143^{*}$ & 0.0727 & $0.149^{*}$ & $0.134^{*}$ & 0.0371 \\
\hline & $(0.0537)$ & $(0.0555)$ & $(0.0608)$ & $(0.0600)$ & $(0.0621)$ & $(0.0828)$ \\
\hline \multirow[t]{2}{*}{ Media satisfaction } & $0.191^{* *}$ & $0.238^{* * *}$ & $0.223^{* *}$ & $0.181^{*}$ & $0.171^{*}$ & 0.142 \\
\hline & $(0.0686)$ & $(0.0710)$ & $(0.0778)$ & $(0.0767)$ & $(0.0795)$ & $(0.106)$ \\
\hline \multirow[t]{2}{*}{ Media dependence } & $0.126^{* *}$ & $0.124^{*}$ & $0.113^{*}$ & $0.143^{* *}$ & $0.163^{* *}$ & 0.0863 \\
\hline & $(0.0483)$ & $(0.0499)$ & $(0.0547)$ & $(0.0539)$ & $(0.0559)$ & $(0.0744)$ \\
\hline \multirow[t]{2}{*}{$\begin{array}{l}\text { Media access to } \\
\text { information }\end{array}$} & $0.107^{*}$ & 0.0799 & 0.0729 & $0.147^{* *}$ & $0.126^{*}$ & 0.107 \\
\hline & $(0.0473)$ & $(0.0489)$ & $(0.0536)$ & $(0.0528)$ & $(0.0547)$ & $(0.0729)$ \\
\hline \multirow[t]{2}{*}{$\begin{array}{l}\text { Media social } \\
\text { interaction }\end{array}$} & 0.0862 & $0.130^{*}$ & 0.0810 & 0.0769 & 0.0932 & 0.0502 \\
\hline & $(0.0559)$ & $(0.0578)$ & $(0.0634)$ & $(0.0625)$ & $(0.0647)$ & $(0.0862)$ \\
\hline \multirow[t]{2}{*}{ Constant item } & $2.008^{* * *}$ & $1.535^{* * *}$ & $2.236^{* * *}$ & $1.812^{* * *}$ & $1.802^{* * *}$ & $2.657^{* * *}$ \\
\hline & $(0.288)$ & $(0.298)$ & $(0.326)$ & $(0.322)$ & $(0.333)$ & $(0.444)$ \\
\hline The total number & 208 & 208 & 208 & 208 & 208 & 208 \\
\hline Decision coefficient & 0.286 & 0.315 & 0.222 & 0.284 & 0.268 & 0.106 \\
\hline
\end{tabular}

Notes. Brackets in the digital is standard error. ${ }^{*} p<0.05,{ }^{* *} p<0.01,{ }^{* * *} p<0.001$.

\section{Interview Analysis}

The results above suggest that intercultural experience and host social media usage enhance intercultural adaptability of international students: Existing intercultural experience can help reduce the sense of strangeness and the impact of cultural differences; host social media usage can help improve interpersonal interaction, campus adaptation, and academic performance, especially when international students spend more time chatting with Chinese friends or have higher media satisfaction, media dependency, and more frequent access to information.

In order to further verify the conclusion, interviews were conducted through class WeChat Group where international students gathered, and found that information about study, examination and after-school gathering were most frequently shared in the group, and there was a strong interaction between teachers and students. As 
for Wechat Moments, most students would like to release information or praise comments to interact with others. All of these demonstrate that WeChat had been helping them a lot in intercultural adaptation to a certain extent.

However, results of the questionnaire survey showed that students with cultural distances and lower Chinese proficiency have better intercultural adaptation, which is against the original hypothesis of this study. Therefore, interview was applied as necessary study supplement. Five students with high/low Chinese proficiency were selected from Asia and non-Asia, and the interview covered 20 students in total. All these students being interviewed were asked to answer three questions: Do you think your cross-cultural adaptability better than others? What do you think is the main reason? Do you think that language proficiency is one of the reasons and why?

It could be concluded from the interview that reasons for students with cultural distance and lower Chinese proficiency having better intercultural adaptation lies in that, for one hand, African make up the vast majority of students from non-Asian country, whose passion and enthusiasm makes them more adaptive in new environment; for another, with the bilateral relations between China and Africa getting increasingly solid, a growing number of African students choose to study in China, which to some extent may let them feel kind of at home because of the support they can obtain from both countries and their peers. Besides, students with lower Chinese proficiency spend most of their spare time with Chinese friends or traveling, which can be beneficial to their intercultural adaptability, while those with better Chinese proficiency are quite the opposite for the reason that they care more about their own study, which eventually leads to their slight misfit in maintaining personal interest, campus integration and ecological adaptation. What is more, host social media usage is not a key variable affecting intercultural adaptation. Students who spend longer on host social media said that they were mainly keeping in touch with national friends in China or killing time. But the variable of "average daily interaction time with Chinese" indicates that students spending more time chatting with Chinese can better adapt to life in China.

\section{Conclusions}

Taken together what have been analyzed and discussed specifically above, it can be summarized that the use of host social media can help with the improvements of international students' intercultural adaptability, and push forward their integration into another cultural environment. As host social media plays such an important role in the education and intercultural adaptation of international students, at the end of this thesis, suggestions aiming at making good use of it are put forward as follow.

Teaching Chinese as a second language (TCSL) teachers might as well try to explore the informational and educational function of host social media, using it as teaching tool and to strengthen interactions between teachers and students. As what the findings have showed us, most international students use host social media for an average of more than two hours a day and have high satisfaction or dependence on it, which exert significant impacts on their intercultural adaptation in China. Thus, teachers should make full use of the debris time to give students more support in daily life.

International student managers should actively guide international students how to use host social media correctly and to carry out self-ideological and cultural education. Besides, attention should be paid as well to the promotion of legitimacy, security, and appropriateness of international students' access to social networking through WeChat Groups or other ways. Also, preventing students from being over addicted to social 
networking is necessary. Last but not least, it could be helpful with international students' adaptability by using host social media to pass on China's traditional culture and modern culture, and thus proceed to enhance their cultural identity.

International students in China should first fully realize the importance of host social media in their study and lives in China, then make good use of host social media's functions to interact with local Chinese and know more about the current situation of China's development. In so doing, they can probably help themselves adapt more readily and enrich their life and learning journey in China.

\section{References}

Chen, H. L. (2012). Research on the strategic adjustment of education of international students in china. Research in Higher Education of Engineering, 2, 86-91.

Dodd, C. H. (2006). Cross-cultural communication motivation (5th ed.). China: Shanghai Foreign Language Education Press.

Lou, S. J. (2017). On the strategy of borrowing non-native social media from Taiwan military broadcasting. China Broadcasts, 8 , 29-32.

Mayfield, $\quad$ A. (2010). What is social media? Retrieved from http://www.Icrossing.Co.uk/fileadmin/uploads/eBooks/What_is_Social_Media_iCrossing_ebook.pdf

National Association of Foreign Student Affairs (NAFSA). (2017). NAFSA international student economic value tool. Retrieved from

http://www.nafsa.org/Policy_and_Advocacy/Policy_Resources/Policy_Trends_and_Data/NAFSA_International_Student_Ec onomic_Value_Tool/

Open Doors. (2017). Economic impact of international students. Retrieved from https://www.iie.org/Research-and-Insights/Open-Doors/Data/Economic-Impact-of-International-Students

Park, R. E. (1922). The immigrant press and its control. New York: Harper.

Searle, W., \& Ward, C. (1990). The prediction of psychological and sociocultural adjustment during cross-cultural transitions. International Journal of Intercultural Relations, 14(4), 449-464.

Wang, H. D., \& Wang, X. (2013). Digital sojourner-Transmutations of the interaction between new media usage and acculturation of sojourners. Retrieved from http://en.cnki.com.cn/Article_en/CJFDTOTAL-XWCP201300019.htm

Wang, S. L. (2014). Investigation and research on the second language learning strategies of the preparatory students of the China Scholarship Council. Social Science Front, 2, 258-260.

Wang, Y. M., \& Xie, N. (2017). Chinese international students education in the background of internationalization of higher education. China Adult Education, 24, 64-66.

Ward, C., \& Kennedy, A. (1999). The measurement of sociocultural adaptation. International Journal of Intercultural Relations, 23(4), 659-677.

Wen, W., Liu, J. Q., Hu, D., \& Chen, Q. (2014). An empirical study of intercultural adaptation of international students in China and its determinants. Fudan Education Forum, 12(5), 50-57.

Wilson, J. (2013). Exploring the past, present and future of cultural competency research: The revision and expansion of the sociocultural adaption construct (Unpublished doctoral dissertation, Victoria University of Wellington).

Yang, J. H. (2005). Study of international adaptation problems of international students in China (Unpublished doctoral dissertation, East China Normal University).

Zhao, Y. Z., Zhang, J. W., XIE, W. J., \& YU, J. S. (2015). "Social media”?-Translation and analysis of a set of crucial concepts. Journalism Review, 6, 63-66.

Zhou, L. L., \& Laingonirina, F. C. (2016). A review of media use and intercultural adaptation studies. Journal of Education and Media Studies, 2, 92-95. 